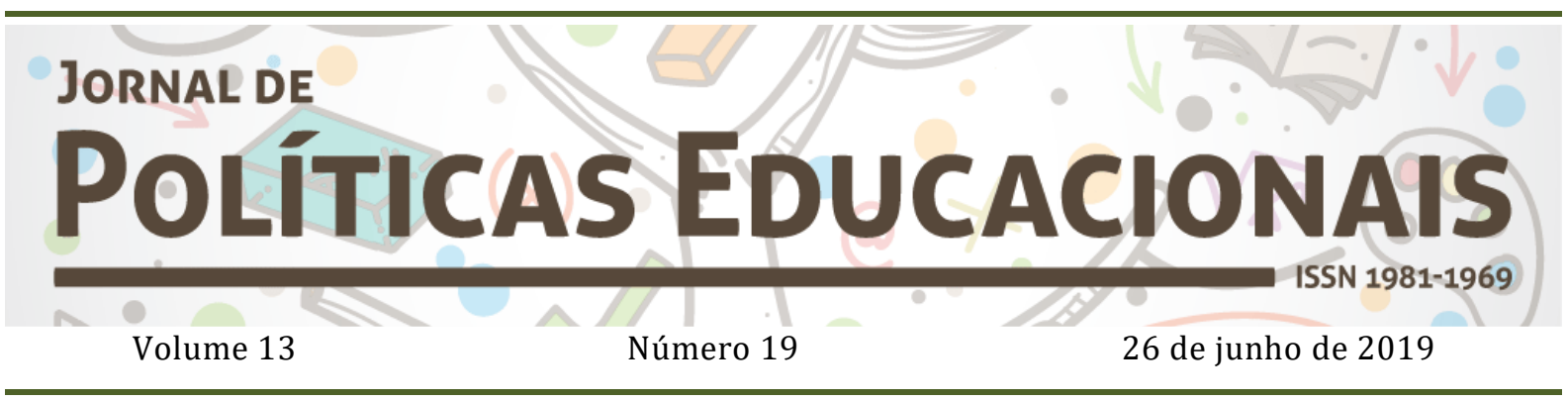

\title{
Mapeamento de teses e dissertações sobre gênero, diversidade sexual e formação inicial docente no Brasil
}

\section{Mapping of theses and dissertations on gender, sexual diversity and initial teacher education in Brazil}

\section{Mapeo de tesis y disertaciones sobre género, diversidad sexual y formación inicial docente en Brasil}

Citação: SOARES, A. G. Mapeamento de teses e dissertações sobre gênero, diversidade sexual e formação inicial docente no Brasil. Jornal de Políticas Educacionais. V. 13, n. 19. junho de 2019.

http:// 10.5380/ipe.v13i0.64555

\begin{abstract}
Resumo:
Neste artigo, busco examinar a produção científica sobre a formação docente, especialmente o curso de Pedagogia, e a abordagem de gênero, sexualidade e diversidade sexual na formação inicial. 0 tipo de pesquisa utilizada foi de caráter bibliográfico e documental, na perspectiva de mapear a literatura sobre o assunto, cujas fontes permearam teses e dissertações da base de dados da fundação Coordenação de Aperfeiçoamento de Pessoal de Nível Superior (CAPES), e relatórios de pesquisa. 0 tratamento metodológico das fontes de pesquisa efetivou-se por meio da análise crítica das produções científicas e documentais. Os resultados encontrados revelam que a maior parte das teses e dissertações concentramse na identidade profissional e os diversos aspectos que permeiam a percepção da identidade docente; o segundo grupo de trabalhos de pesquisas focaliza a inserção da temática de gênero e sexualidade nas matrizes curriculares do curso de Pedagogia em Instituições Públicas de Ensino Superior; o terceiro eixo de pesquisas está centrado em análises dos discursos dos discentes do curso de Pedagogia e a abordagem da temática das relações de gênero e sexualidade.
\end{abstract}

Palavras-chaves: Gênero e diversidade sexual; Formação inicial; Política educacional.

\footnotetext{
${ }^{1}$ Doutor em Educação pela Universidade de São Paulo (USP). Professor Adjunto na Faculdade Única de Contagem. Coordenador Pedagógico no $1^{\circ}$ e $2^{\circ}$ Ciclo na Prefeitura de Belo Horizonte. E-mail: prof.alexhis@gmail.com. ORCID: http://orcid.org/0000-0001-6835-1155. Agradeço a leitura atenta de Miria Kátia e Sérgio T. da Silva.
} 


\begin{abstract}
:
In this article I seek to examine the scientific production on teacher education, especially the Pedagogy course and the approach to gender, sexuality and sexual diversity in initial formation. The type of research used was of a bibliographical and documentary nature with the perspective of mapping the literature on the subject, whose sources permeated theses and dissertations of the Database of the Coordination Foundation for the Improvement of Higher Education Personnel (CAPES) and research reports. The methodological treatment of the sources of research was effected through a critical analysis of the scientific and documentary productions. The results show that most theses and dissertations focus on the professional identity and the various aspects that permeate the perception of the teaching identity; the second group of research studies focused on the insertion of the theme of gender and sexuality in the curricular matrices of the Pedagogy course in Public Institutions of Higher Education; in the third axis of researches are centered in analyzes of the discourses of the students of the course of Pedagogy and the approach of the subject of the relations of gender and sexuality.
\end{abstract}

Keywords: Gender and sexual diversity; Initial formation; Educational politics.

\title{
Resumen:
}

En este artículo busco examinar la producción científica sobre la formación docente, especialmente el curso de Pedagogía y el abordaje de género, sexualidad y diversidad sexual en la formación inicial. El tipo de investigación utilizado fue de carácter bibliográfico y documental en la perspectiva de mapear la literatura sobre el tema, cuyas fuentes permearon tesis y disertaciones de la Base de datos de la Fundación Coordinación de Perfeccionamiento de Personal de Nivel Superior (CAPES) e informes de investigación. El tratamiento metodológico de las fuentes de investigación se efectúa por medio del análisis crítico de las producciones científicas y documentales. Los resultados encontrados revelan que la mayor parte de las tesis y disertaciones se concentran en la identidad profesional y los diversos aspectos que permean la percepción de la identidad docente; el segundo grupo de trabajos de investigación enfocaron la inserción de la temática de género y sexualidad en las matrices curriculares del curso de Pedagogía en Instituciones Públicas de Enseñanza Superior; en el tercer eje de investigaciones están centradas en análisis de los discursos de los discentes del curso de Pedagogía y el abordaje de la temática de las relaciones de género y sexualidad.

Palabras claves: Género y diversidad sexual; Formación inicial; Política educativa.

\section{Introdução}

Os campos teóricos que se constituíram a partir de ou em conjunto com os movimentos sociais tiveram e continuam tendo efeitos imensos. Minha aposta é que as transformações trazidas por esses campos ultrapassam o terreno dos gêneros e da sexualidade e podem nos levar a pensar, de um modo renovado, não só a educação, mas a cultura, as instituições, o poder, as formas de aprender e de estar no mundo. (LOURO, 2011, p. 69)

Neste artigo, busco mapear e examinar a produção científica sobre a formação inicial em Pedagogia com foco em gênero, sexualidade e diversidade sexual. A busca pelo mapeamento e análise das produções acadêmicas, no âmbito dos marcadores de gênero e diversidade sexual, na área de educação possibilita, também, visualizar a expansão de estudos e como tem se realizado a aproximação com outras áreas do conhecimento como a Antropologia, Sociologia, Ciências Exatas, Engenharia. Cabe salientar que a produção acadêmica deve ter como compromisso a redução das desigualdades sociais em um país que tem apresentado um cenário de avanços e retrocessos no âmbito das políticas educacionais. 
No Brasil, as discussões sobre gênero e sexualidade surgiram timidamente a partir do debate impulsionado pela Constituição Federal de 1988 e, já na década de 1990, pelas leis e planos que se seguiram, entre eles, a nova Lei de Diretrizes e Bases da Educação Nacional (Lei no 9394/1996) e por meio dos Parâmetros Curriculares Nacionais (1997), a partir do qual a União assumiu o compromisso de construir uma reformulação curricular em substituição ao antigo currículo mínimo comum (ALTMANN, 2001; VIANNA; UNBEHAUM, 2004, 2006).

Fúlvia Rosemberg e Nina Madsen (2011) destacam, no contexto das reformas da década de 1990, que as agendas de gênero e de educação se entrecruzaram no Brasil em atendimento aos compromissos internacionais com foco específico no acesso das mulheres à educação.

Para compreensão desses marcadores, a diversidade sexual e de gênero são termos polissêmicos e estão imbricados. Além disso, a perspectiva adotada neste trabalho se opõe à perspectiva binária e enviesada pela concepção heteronormativa. Isso requer a compreensão da existência de diversas expressões de masculinidade e feminilidade, inclusive de que os sujeitos podem se situar na fronteira entre elas, demonstrar expressões de forma alternada ou expor novas expressões de gênero. A noção de diversidade sexual envolve distintas identidades de gênero e orientações sexuais, inclui uma perspectiva de combate à LGBTfobia, ao heterossexismo, e a problematização da heteronormatividade. (CARVALHO; ANDRADE; JUNQUEIRA, 2009).

Assim sendo, o texto está estruturado em quatro partes, contendo esta introdução. $\mathrm{Na}$ segunda parte, apresento um breve recorte a respeito da agenda de gênero, sexualidade e diversidade sexual na esfera da política educacional, com recorte temporal do fim do século XX e a primeira década do século XXI. Na terceira parte, realizo o mapeamento da produção acadêmica com foco na formação docente e a relação com a política educacional. Nas considerações finais, busco identificar o empenho na área da educação em implementar disciplinas obrigatórias ou optativas na formação inicial, bem como a oferta de disciplinas na perspectiva transversal, e os desafios para o debate de gênero e diversidade sexual na formação inicial docente. 0 presente estudo é compreendido como uma pesquisa bibliográfica e documental, de natureza qualitativa, cuja perspectiva buscou mapear a literatura sobre o assunto 
SOARES, A. G. Mapeamento de teses e dissertações sobre gênero, diversidade sexual e formação inicial docente no Brasil

\subsection{Breve recorte sobre a agenda de gênero, sexualidade e diversidade sexual no âmbito da política educacional}

A proposta de refletir sobre o planejamento de gênero, sexualidade e diversidade sexual e sua interface com a política educacional requer inicialmente introduzir uma percepção sobre política educacional. Para Dalila O. Andrade (2010, p.2) pode-se entender este campo como ações

[...] dirigidas à noção de justiça social, de promoção da igualdade entre os indivíduos, independente de sua condição econômica. 0 ideal de igualdade de oportunidades e a laicidade do ensino que orientou desde os primórdios a organização dos sistemas escolares republicanos podem ser considerados os principais vetores da política educacional do Século $\mathrm{XX}$.

Partindo dessa apreensão, o processo de construção dessas agendas de gênero e diversidade sexual na educação deu-se juntamente com os movimentos sociais que propunham, com a abertura política, repensar o papel da escola e dos conteúdos por ela trabalhados, fato relacionado ao amplo processo de questionamento de valores e formas de organização social, por meio de mobilizações populares, em especial a dos movimentos feministas em várias partes do mundo.

Em sua análise sobre políticas públicas de educação, do ponto de vista das relações sociais de gênero, "tanto o Estado quanto os movimentos, nas suas respectivas pluralidades, articulam-se e/ou disputam acirradamente interesses sociais que se fazem presentes nesse processo" (Vianna, 2012, p. 130). Cláudia Vianna (2012) descreve um campo de tensões, repleto de negociações, no qual se evidencia a supressão e/ou concretização das reformas, dos planos, projetos, programas e outras ações implementadas separadas ou articuladamente entre o Estado e movimentos sociais.

Ainda sobre a relação entre Estado e movimentos sociais, na produção das políticas públicas de educação voltadas para o gênero e para a diversidade sexual no governo de Luiz Inácio Lula da Silva, a pesquisadora Cláudia Vianna (2015) destaca o papel dos movimentos sociais de pessoas Lésbicas, Gays, Bissexuais, Transexuais e Transgêneros $(\text { LGBT })^{2}$ na tentativa de configuração de uma agenda voltada para essa temática na

\footnotetext{
${ }^{2}$ São muitas as siglas que procuram representar o movimento LGBT no Brasil. Neste trabalho adoto a sigla LGBT (Lésbicas, Gays, Bissexuais, Travestis, Transexuais e Transgêneros), seguindo deliberação da I Conferência Nacional LGBT, realizada em 2008.
} 
SOARES, A. G. Mapeamento de teses e dissertações sobre gênero, diversidade sexual e formação inicial docente no Brasil

educação. Pessoas LGBT passam de "temas polêmicos" a "sujeitos de direitos" nas políticas públicas de direitos humanos e de educação; a denúncia da violência física, enquanto justificativa de políticas, vai cedendo espaço para propostas de superação das desigualdades.

Ainda nesse sentido, cabe salientar que a análise e o questionamento das políticas implementadas por diferentes níveis de governo, em um país de constituição federativa como é o Brasil, por grupos sociais distintos com seus interesses e necessidades específicos, traduzem nova perspectiva de vida e demandas sociais. Na mesma direção, os estudos mostram o apoio do Ministério da Educação (MEC) às demandas da Secretaria Especial de Políticas para Mulheres (SPM), criada em 2003, na formulação de propostas voltadas para a sexualidade, a homossexualidade e as relações de gênero.

De acordo com Fúlvia Rosemberg e Nina Madsen (2011), com o progresso das mulheres na educação brasileira no período 2003-2009 no plano da justiça redistributiva, houve melhoria dos indicadores educacionais das mulheres, não distante de intensas desigualdades etárias, étnico-raciais, regionais e socioeconômicas, que atingem mulheres e homens.

No âmbito do reconhecimento, as autoras detectaram mais desafios que avanços, seja no plano das mudanças na legislação educacional, seja no plano curricular e didático. Especialmente a elaboração de conteúdo - não apenas isentos de componentes discriminatórios explícitos, mas capazes de contribuir para a construção da igualdade -, foi tarefa que pouco avançou ao longo da década de 2000. Já no âmbito da justiça representativa, debate que ultrapassa as fronteiras do campo educacional e está relacionado a outras demandas, inclusive por mais mulheres em espaços de poder, notouse forte estagnação e em alguns casos uma retração ${ }^{3}$.

O foco principal das políticas educacionais, que procuraram introduzir as temáticas de gênero e diversidade sexual, foi o currículo, com destaque para os

\footnotetext{
${ }^{3}$ Segundo um levantamento do Departamento Intersindical de Assessoria Parlamentar (DIAP), em 2014, apesar da mudança na legislação eleitoral, que assegura a presença de pelo menos $30 \%$ de mulheres nas listas eleitorais dos partidos, a representação feminina na Câmara, com apenas 51 das 513 cadeiras, está muito aquém da importância da mulher na sociedade. Mesmo tendo crescido em relação à eleição de 2010, quando foram eleitas 45 , a grande verdade é que os partidos não priorizam as campanhas femininas, apenas cumprem a cota exigida na lei. Enquanto não houver uma reforma política que feche a lista e garanta a alternância de sexo, as mulheres continuarão sub-representadas no Parlamento. (Departamento Intersindical de Assessoria Parlamentar, 2014, p.39)
} 
Parâmetros Curriculares Nacionais e formação docente, esse último recebe forte incentivo a partir do Programa Brasil sem Homofobia (BSH).

O Programa Brasil Sem Homofobia foi realizado por meio de uma ação definida no Plano Plurianual - PPA 2004-2007. Tal ato deliberou na esfera do Programa Direitos Humanos, Direitos de Todos a ação denominada Elaboração do Plano de Combate à Discriminação contra Homossexuais. O BSH, programa de combate à violência e à discriminação contra GLTB ${ }^{4}$ e de promoção da cidadania homossexual, teve como objetivo promover a cidadania de gays, lésbicas, travestis, transgêneros e bissexuais, a partir da equiparação de direitos e do combate à violência e à discriminação homofóbicas, respeitando a especificidade de cada um desses grupos populacionais (CONSELHO, 2004).

Marcelo Daniliauskas (2011) indica que, no momento inicial, o BSH voltou-se para questões de violência física e assassinatos de homossexuais. Houve posteriormente a abordagem de outros temas, como, por exemplo, a cidadania, problematizando a questão da desigualdade de direitos, o que denotou um progresso no tratamento da questão por parte do governo e da agenda LGBT com a perspectiva de justiça social.

Além do mais, a proposta do BSH visava mudanças de comportamentos e preconcepções, inclusive de gestores públicos por meio da educação. 0 documento apresenta no Programa de Ações - tópico V - Direito à Educação: promovendo valores de respeito à paz e à não discriminação por orientação sexual - um delineamento específico sobre o fomento e apoio a cursos de formação inicial e continuada de professores na área da sexualidade, bem como o incentivo na produção de materiais educativos de apoio e divulgação da produção de materiais específicos para a formação de professores (CONSELHO, 2004, p.22).

Os estudos mais recentes destacam a importância do BSH no incentivo à formação docente (DANILIAUSKAS, 2011; FERNANDES, 2011; ROSSI, 2010, entre outros) e como resultado desse processo de negociação entre o Estado e o movimento LGBT, o MEC passa a responsabilizar-se por ações de combate à homofobia na educação (FERNANDES, 2011).

Um impulso das formulações de políticas públicas pode ser visualizado na modalidade da formação continuada docente com enfoque de gênero, sexualidade e homofobia, por meio do Edital Formação de profissionais da Educação para a Cidadania e Diversidade Sexual, no ano de 2005, criada pelo MEC no domínio da Secretaria de

${ }^{4} \mathrm{O}$ documento apresenta a sigla dessa forma. 
Educação Continuada (SECAD). Houve nesse eixo uma abertura para a participação de instituições públicas e também privadas sem fins lucrativos em todo o Brasil. Sendo publicado novo edital, em 2006, mantendo a finalidade de formação de profissionais da educação, recursos oriundos do Programa Educação para a Diversidade e Cidadania, do Plano Plurianual 2004-2007 (VIANNA, 2015; BRASIL, 2007).

Pode-se notar, com o programa Educação e Gravidez na Adolescência, o objetivo de qualificar os educadores e produzir material didático sob ponto de vista de que os adolescentes ${ }^{5}$ são sujeitos de sua sexualidade e com capacidade e responsabilidade para fazer escolhas. Outra iniciativa foi a execução do Seminário Internacional Educando para a Igualdade de Gênero, Raça e Orientação Sexual, no fim de 2004, que contou com o envolvimento da SPM/PR, a Seppir/PR, o MEC e o British Council, além de pesquisadores/as brasileiras/os e ingleses, e ativistas de organizações não governamentais ligadas aos movimentos negro, de mulheres e GLBTT.

partir desse evento, estabeleceu-se que seria necessária a formação de profissionais da educação nas temáticas de gênero, orientação sexual e relações étnicoraciais. No ano de 2005, foi implantado o Programa de Formação de Profissionais da Educação para a Cidadania e a Diversidade Sexual, cujo objetivo era apoiar experiênciaspiloto e adquirir subsídios para a formulação de políticas educacionais de valorização e respeito à diversidade sexual e de combate à homofobia. No ano seguinte ocorreu a criação do 1ํo Prêmio Construindo a Igualdade de Gênero, cuja finalidade era valorizar as produções que são classificadas em redações e trabalhos científicos monográficos. Essa iniciativa é parte complementar do Programa Mulher e Ciência, constituído com o objetivo de estimular a produção científica e a reflexão acerca das relações de gênero, mulheres e feminismos no país, inclusive promover a participação das mulheres no campo das ciências e carreiras acadêmicas (BRASIL, 2006).

Em 2006, a Secad, em conjunto com a Secretaria Especial dos Direitos Humanos (Sedh/PR), lança novo edital para Projetos de Formação de Profissionais da Educação para a Promoção da Cultura de Reconhecimento da Diversidade Sexual e a Igualdade de Gênero, com vista a incrementar a realização de projetos de formação para o enfrentamento ao sexismo e à homofobia, no ano de 2007 (JUNQUEIRA,2007).

\footnotetext{
${ }^{5}$ Vale destacar que a discussão sobre a faixa etária da adolescência apresenta diversas perspectivas na literatura.
} 
SOARES, A. G. Mapeamento de teses e dissertações sobre gênero, diversidade sexual e formação inicial docente no Brasil

Ainda naquele ano, é implementado o curso Gênero e Diversidade na Escola (GDE), proposta ofertada em um projeto piloto, em 2006, cuja modalidade de certificação variava entre extensão ou aperfeiçoamento. Segundo as diretrizes do programa, a Secretaria Especial de Políticas para as Mulheres e o Ministério da Educação - por meio das Secretarias de Educação a Distância (SEED ${ }^{6}$ ) e a Secretaria de Educação Continuada Alfabetização e Diversidade (SECAD), objetivaram, ao apresentar o curso GDE, proporcionar aos educadores e às educadoras da rede pública do Ensino Básico uma noção de respeito e valorização da diversidade, de forma que fossem abordadas as discussões baseadas nas desigualdades de gênero, orientação sexual e raça/etnia no Brasil, pontos estritamente ligados aos direitos humanos. 0 respectivo programa na linha da formação continuada se ampliou por diversas instituições públicas de ensino superior e tornou-se de grande força e duração.

Em 2008, o GDE passa a ser oferecido pelas universidades brasileiras, articuladas em torno da recém-criada Rede de Educação para a Diversidade e o Sistema Universidade Aberta do Brasil (UAB) ${ }^{7}$. Destaca-se que, até a reestruturação do MEC, implementada pelo Decreto 7.480/2011, cursos destinados à formação docente eram realizados pela Secad ${ }^{8}$, em parceria com a Seed e sob a coordenação da Capes, tendo sido transferidos para o Sistema Universidade Aberta do Brasil (UAB), com o encerramento das atividades da Seed (GATTI et al., 2011). Salienta-se que, "direcionados especificamente aos profissionais das redes oficiais de ensino, os cursos da Rede de Educação para a Diversidade abrem a oferta a outros públicos participantes" (GATTI et al., 2011, p. 69).

0 crescimento das políticas educacionais, que procuram, ainda que precariamente, atender às demandas de gênero e diversidade sexual, é também acompanhado pelo significativo avanço da produção acadêmica sobre o tema. Vianna (2012) registra um número expressivo de pesquisas dedicadas à análise dos Parâmetros Curriculares Nacionais e à crítica das diretrizes sobre Orientação Sexual ${ }^{9}$ contida nele. Diante do

\footnotetext{
${ }^{6}$ Secretaria extinta em 2011.

7 Trata-se de um "sistema integrado por universidades públicas que oferece cursos de nível superior para camadas da população que têm dificuldade de acesso à formação universitária, por meio do uso da metodologia da educação a distância. 0 público em geral é atendido, mas os professores que atuam na educação básica têm prioridade de formação, seguidos dos dirigentes, gestores e trabalhadores em educação básica dos estados, municípios e do Distrito Federal." Disponível em:<http.www.uab.capes.gov.br>.

${ }^{8}$ No ano de 2011, a Secad passou a chamar-se Secadi (Secretaria de Educação Continuada, Alfabetização, Diversidade e Inclusão).

${ }^{9}$ Cabe destacar que a concepção de orientação sexual dos PCN é entendida como sendo de caráter informativo, o que está vinculado à visão de sexualidade que perpassa o documento. A sexualidade é
} 
SOARES, A. G. Mapeamento de teses e dissertações sobre gênero, diversidade sexual e formação inicial docente no Brasil

exposto, cabe salientar a aproximação da produção acadêmica das instituições de ensino superior com a formação docente e com a educação básica, tendo em vista os desafios que os cerca.

Para Maria Isabel de Almeida (2014), é preciso considerar que a formação de professores tem vivido nos tempos atuais o predomínio de uma visão conservadora, sustentada na perspectiva técnico/instrumentalizada, que esvazia o papel do/a professor/a enquanto criador/a e organizador/a de sua prática. Estse cenário é marcado por diversas situações que podem ser exemplificadas pela: a) sobreposição dos conhecimentos teóricos em detrimento dos saberes experienciais; b) distância que separa a formação universitária da realidade das escolas.

\section{Metodologia utilizada para mapear as produções científicas no campo da educação sobre gênero e diversidade sexual}

O presente estudo é compreendido como uma pesquisa bibliográfica e documental, de natureza qualitativa, cuja perspectiva buscou mapear a literatura sobre o assunto. De acordo com Désirée Motta Roth e Graciela Rabuske Hendges (2010), pesquisas desse porte podem oferecer base para posteriores pesquisas experimentais, tendo em vista a definição do que se tem produzido na literatura. A amostra de produções científicas pesquisadas estão distribuídas em todo o território brasileiro e não houve a descrição de vínculo institucional. Cabe mencionar que a metodologia utilizada tem a perspectiva de inventariar, descrever e analisar a produção científica na área da educação.

Com o objetivo de agregar dados dispersos em inúmeras bases, realizei levantamentos na Biblioteca Digital Brasileira de Teses e Dissertações (BDTD), do Instituto Brasileiro de Informação em Ciência e Tecnologia e também na base de dados da Coordenação de Aperfeiçoamento Pessoal de Nível Superior (Capes), cujo período de delimitação de busca foi de 2000 a 2016. Realizei levantamentos na base com os seguintes descritores, tais como: gênero e pedagogia, pedagogia e sexualidade, pedagogia e diversidade sexual, formação de professores e sexualidade, formação de professores e

concebida como um dado da natureza[...]Ela é vista sob o ponto de vista biológico, atrelada às funções hormonais. Quanto à experimentação erótica, à curiosidade e ao desejo, estes são considerados comuns, quando a dois. A potencialidade erótica do corpo a partir da puberdade é concebida como centrada na região genital, enquanto que, à infância, só é admitido um caráter exploratório pré-genital. Os conteúdos devem favorecer a compreensão de que o ato sexual, bem como as carícias genitais, só têm pertinência quando manifestados entre jovens e adultos (ALTMANN, 2001, 580-581). 
SOARES, A. G. Mapeamento de teses e dissertações sobre gênero, diversidade sexual e formação inicial docente no Brasil

gênero, formação de professores e diversidade sexual. Utilizei os operadores boleanos para ter uma melhor performance nos resultados (AND, OR, AND NOT). Além destas pesquisas, realizei buscas nas bibliotecas virtuais da Universidade de São Paulo (USP), na base da Pontifícia Universidade Católica de São Paulo (PUC/SP), e na Biblioteca Ana Maria Poppovic da Fundação Carlos Chagas (FCC).

O mapeamento de dissertações e teses que se aproximavam da temática possibilitou verificar quais os recortes de pesquisa que foram desenvolvidos, além de distinguir as produções que se relacionavam diretamente com o tema específico da formação docente na perspectiva de gênero e/ou diversidade sexual.

Na próxima subseção, indico as pesquisas acadêmicas que permeiam a formação docente, política educacional e os marcadores sociais de gênero e diversidade sexual. Destaco inicialmente que o trabalho tem como foco a formação docente inicial e, nesse sentido, considero relevante situar brevemente a produção acadêmica a respeito da formação continuada docente.

\section{A produção acadêmica sobre a formação docente e a relação com a política educacional}

Pesquisas mais recentes ressaltam a ênfase dessas políticas educacionais em gênero e diversidade sexual na produção de materiais educativos e na formação continuada docente (RIZZATO, 2013; COLETO, 2012; MOSTAFA, 2009; GRÖSZ, 2008; SANTOS, 2012; SANTOS, 2008; CALDAS, 2007; KOERICH, 2007; MAISTRO, 2006).

Uma parte significativa desses trabalhos dá ênfase à análise das políticas de formação continuada docente. Esse é o caso da dissertação de mestrado de Liane Rizzato (2013). A autora buscou as percepções de professores/as sobre gênero, sexualidade e homofobia, e o modo como lidam com tais temáticas na prática docente. Trata-se de uma investigação de natureza qualitativa, cujos sujeitos de pesquisa são professores/as da rede estadual de ensino de São Paulo que participaram de um curso intitulado “Convivendo com a Diversidade Sexual na Escola”, oferecido em 2007. Conforme Rizzato (2013), as contradições e dissonâncias apresentadas nos discursos dos/as entrevistados/as evidenciaram que a construção da experiência social em homofobia por eles(as) vivenciada têm a mesma dinâmica de produção-reprodução-resistência apresentada pela escola no que tange às relações gênero e sexualidade. 
Tendo em vista essa dinâmica, e considerando as políticas educacionais, Bernadete Gatti, Elba Barreto e Marli André (2011), na obra Políticas docentes no Brasil, destacam que o delineamento qualitativo da formação docente compete à legislação vigente, à União e aos seus órgãos. As autoras alertam que políticas mais fortes do MEC estão centradas na expansão da oferta das licenciaturas, e muito pouco em sua qualidade curricular. Não obstante, ações governamentais de formação docente estão direcionadas para os sujeitos que exercem a profissão e buscam esta ação, conhecida na área de educação como formação continuada, em especial na modalidade a distância, o que evidencia uma ação reduzida na formação inicial.

No entanto, Wivian Weller e Cláudia Denís Paz (2011) ressaltam que há escassez de estudos sobre as políticas educacionais com enfoque de gênero na Educação Básica, notadamente na formação de professores, e que o desenvolvimento de ações concretas requer um sistema de acompanhamento e avaliação, assim como estudos teóricos e pesquisas empíricas que possam contribuir para a fundamentação dos programas educacionais voltados para a redução das desigualdades de gênero e diversidade.

Na próxima seção busco delinear o levantamento de dissertações e teses que encontrei sobre gênero, sexualidade e diversidade sexual produzidas em programas de pós-graduação na área de educação.

\subsection{Mapeamento de dissertações e teses sobre gênero e diversidade sexual}

Diante do exposto, procurei ler as publicações na possibilidade de identificar os recortes de pesquisas, busquei agrupá-las em três categorias iniciais, tais como: i) a presença de mulheres e homens nos cursos de Pedagogia, Normal Superior e Técnico/a em Magistério; ii) identidade profissional gestada nesse processo de formação docente; iii) o currículo dessa formação a partir da ótica de gênero.

$\mathrm{Na}$ primeira categoria - A presença de mulheres e homens nos cursos de Pedagogia, Normal Superior e Técnico/a em Magistério refere-se à escolha dos cursos de formação vinculados aos marcadores de gênero e diversidade. Tal categoria busca delinear características das produções que permeiam sentimentos, pertencimentos dos sujeitos na formação. Localizei as pesquisas que focam a inserção e presença de mulheres e homens nos cursos de Pedagogia, Normal Superior e Técnico/a em Magistério. 
SOARES, A. G. Mapeamento de teses e dissertações sobre gênero, diversidade sexual e formação inicial docente no Brasil

Nesse sentido, a produção aqui arrolada discute a presença de mulheres e homens nos cursos de Pedagogia, Normal Superior e Técnico/a em Magistério (LOPES, 1996; RIBEIRO, 1998; OLIVEIRA, 2002; VIEIRA, 2003; ABREU, 2003; SILVEIRA, 2006, MARAFON, 2006; LEÃO, 2009; FONSECA, 2011; RAMOS, 2011; VIEIRA, 2012; ROSA, 2012; PEREIRA, 2013; GOMIDES, 2014; SILVA, 2014).

Sobre a inserção de mulheres nos cursos de Pedagogia, cabe ressaltar que a presença majoritária de mulheres caminha na esteira de reflexões mais antigas que problematizam a predominância de mulheres na formação. Vianna (2013) descreve que é preciso olhar além da presença do sexo feminino; a entrada das mulheres no magistério deve ser examinada a partir das relações de classe e gênero. Ainda no tema da feminização do magistério, mas agora com foco em seu avesso, outro grupo de dissertações e teses discute a presença masculina na formação e no exercício da docência.

Na segunda categoria - A identidade profissional gestada nesse processo de formação docente - é caracterizada por produções científicas que estão centradas na composição de atributos, vivências e experiências das/os docentes na realização de suas atividades nas instituições. Os atributos e experiências podem ser visualizadas no âmbito da elaboração da identidade profissional e marcada por relações com seu ambiente de trabalho, com seu grupo profissional. Nesse plano, compreende-se símbolos e significados estabelecidos nessas relações do mundo do trabalho, da identidade profissional docente.Sobre a identidade profissional, entendo na mesma perspectiva de Maria Manuela Garcia (2010) ao descrever um

[...] conjunto de características, experiências e posições de sujeito atribuídas (e autoatribuídas) por diferentes discursos e agentes sociais aos docentes no exercício de suas funções, em instituições educacionais mais ou menos complexas e burocráticas (GARCIA, 2010, p.1).

No que tange à identidade profissional gestada nesse processo de formação docente foram encontradas produções (VIEIRA, 1998; CHAIGAR,2001; BARBOSA, 2002; GARCIA, 2002; VASCONCELOS, 2003; WELK, 2003; COSTA, 2003; SARAIVA, 2003; FERREIRA, 2003; CARDOSO, 2004; CHAGAS, 2004; PEREIRA, 2006; ARAÚJO, 2007; EMBIRUSSU, 2007; ALVARENGA, 2008; ABREU, 2008; SANTOS, 2008; CARVALHO, 2008; SILVA, 2009; BUFALO, 2009; CASTRO, 2010; BARBACELI, 2013; MONTEIRO, 2014; CAPITANIO, 2014). 
Neste campo teórico, Tardif; Lessard; Lahaye, (1991) e Tardif (2002) analisam também como as experiências se configuram na construção das identidades dos profissionais, com base em biografias e memórias dos docentes e os sentidos que atribuem às suas experiências.

Na terceira categoria - 0 currículo dessa formação a partir da ótica de gênero foram identificadas pesquisas que analisaram o currículo no âmbito da formação e sua estreita vinculação com os marcadores sociais de gênero. Compreende-se os elementos de gênero e diversidade sexual acionados na sala de aula, no projeto político pedagógico ou nos planos de ensino propostos no currículo escolar.

Quando examina mais especificamente o currículo dessa formação a partir da ótica de gênero (FREITAS, 2002; NUNES,2002; GAMA, 2004; RIZZA, 2005; BENITES, 2006; BALESTRIN, 2007; KOERICH, 2007; FURTADO, 2007; FRANÇA, 2008; LIMA, 2008; COSTA, 2009; SANTOS, 2006; SANTOS, 2009; SANTOS, 2011; CAMPOS, 2011; REIS, 2011; MARTINS, 2012; SILVA, 2012; FERREIRA, 2013; HAMPEL 2013; CASTRO, 2014; COSTA, 2014; UNBEHAUM, 2014).

Diante do exposto, pode-se realizar alguns apontamentos sobre os principais resultados desses grupos, tais como: 1) a maior parte das teses e dissertações (vinte e quatro) enfocaram na identidade profissional e os diversos aspectos que permeiam a percepção da identidade docente; 2) o segundo grupo de trabalhos de pesquisas (vinte e três) focaliza a inserção da temática de gênero e sexualidade nas matrizes curriculares do curso de Pedagogia em Instituições Públicas de Ensino Superior; 3) o terceiro eixo de pesquisas (quinze) está centrado em análises dos discursos dos discentes do curso de Pedagogia e a abordagem da temática das relações de gênero e sexualidade.

Pelo exposto, é possível notar que na produção acadêmica destaca-se a enorme dificuldade de inserir o tema na formação inicial em Pedagogia. Evidencia-se, também, no mapeamento dessas pesquisas, alguns pontos fundamentais para compreender como tem-se delineado o campo da formação inicial em Pedagogia com foco em gênero, sexualidade e diversidade sexual, tais como: i) egressas do curso de Pedagogia ainda apresentam dificuldades de visualizar e intervir nos marcadores sociais de gênero na escola e na sociedade; ii) as disciplinas com foco em sexualidade figuram na matriz curricular como obrigatórias e optativas e apresentam limites para sua identificação em algumas instituições nas universidades federais; iii) as temáticas sexualidade e gênero, mesmo presentes no curso de Pedagogia, desenvolvem-se como fragmentadas ou isoladas 
enquanto disciplinas na percepção das graduandas; iv) nota-se que a percepção de estudantes da formação inicial sobre gênero é marcada pelo caráter biologizante e demonstram naturalização dos estereótipos sexistas; v) há uma carência de disciplinas e discussões voltadas para sexualidade e gênero na formação inicial; vi) constatou-se que a oferta de disciplinas na licenciatura de Pedagogia é um campo distinto para as discussões de gênero, sexualidade e diversidade, bem como o movimento de políticas educacionais proporcionam novos efeitos; vii) a universidade ocupa uma importante função no debate da formação docente com foco em gênero e sexualidade; viii) houve avanços na relação entre educação e gênero na formação de professores/as, mas ainda carece de uma maior articulação. Além disso, a discussão de gênero tem se desenvolvido na formação docente de forma transversal nas disciplinas regulares, eletivas ou optativas.

\section{Considerações Finais}

Ao realizar o mapeamento da produção de dissertações e teses com ênfase em gênero e diversidade sexual na formação inicial, identifiquei a relação existente entre as pesquisas e a complementaridade nos estudos. Cabe destacar a necessidade de estudos sobre as temáticas mencionadas, pois a educação básica carece de estudos nesses marcadores sociais, sistematizações de práticas pedagógicas da docência e a inserção de disciplinas na formação dos profissionais da educação.

O artigo teve como objeto a análise de dissertações e teses sobre a formação inicial docente com foco em gênero e diversidade sexual. Propôs mapear a produção com ênfase nesses marcadores sociais e indicar em quais grupos ou temas a produção tem se concentrado, bem como sua relação com a formação inicial no contexto das políticas educacionais. Refletir sobre gênero, sexualidade e diversidade sexual é considerar esses temas a partir da perspectiva dos direitos e respectivamente os reflexos no âmbito político, cultural e social, pois essa discussão tem origens nas Conferências do Cairo e Beijin na década de 1990 onde se originou os Direitos Sexuais e Direitos Reprodutivos. Por sua vez, o Brasil é signatário desses tratados, e, assim sendo, há impactos do debate de gênero e diversidade na educação e nas políticas públicas.

Cabe destacar que desde o governo Fernando Henrique Cardoso (FHC) já existia pressão externa para a inserção de gênero, que surge pontualmente com os PCN. No período do governo Lula, tem-se alguns avanços e recuos nesse debate e em relação aos 
movimentos sociais, especialmente: Feminista e LGBT, com demandas que conseguem ser inseridas. Nesse ponto, o debate avança, pois a formação e o currículo ganham prioridade nas oportunidades de se pensar a inserção do debate de gênero e sexualidade nas instituições educacionais. Tais discussões sobre gênero e sexualidade alcançam no primeiro momento a materialidade por meio de diretrizes curriculares para a formação docente, PCN, referenciais curriculares e, em segunda oportunidade e de forma intensa, via formação continuada docente.

Foi possível notar, por um lado, um empenho na área da educação em implementar disciplinas obrigatórias ou optativas na formação inicial, bem como a oferta de disciplinas na perspectiva transversal. Por outro lado, ainda observa-se diversos desafios para o debate de gênero e diversidade sexual na formação inicial docente, tais como: a luta por espaços dentro da matriz curricular no âmbito institucional; a percepção e compreensão pelos/as discentes da relevância desses marcadores para sua prática pedagógica; a ampliação do diálogo para além dos espaços não escolares; a ruptura de estereótipos; e papéis difundidos por instituições religiosas.

Este estudo indicou também a necessidade de ampliação de pesquisas (dissertações e teses) na formação inicial em Pedagogia e demais licenciaturas. Além disso, produções que possibilitem o registro de práticas sobre gênero e diversidade sexual na educação básica na perspectiva de entendimento de uma educação humanista.

\section{Referências}

ABREU, Janette Maria França de. Relações de gênero e suas influências na escolha do curso de Pedagogia do Campus I da Universidade Federal do Maranhão. $171 \mathrm{f}$. 2008. Dissertação (Mestrado em Educação) - Faculdade de Educação, Universidade Federal do Maranhão, Maranhão, 2008.

ABREU, Jânio Jorge Vieira de. Educação e gênero: homens no magistério primário de Teresina (1960 a 2000). Dissertação (Mestrado em Educação) - Universidade Federal do Piauí, Piauí, 2003.

ALMEIDA, Maria Isabel de; PIMENTA, Selma Garrido (Orgs.). Estágios supervisionados na formação docente: educação básica e educação de jovens e adultos. São Paulo: Cortez, 2014.

ALVARENGA, Carolina Faria. Relações de gênero e trabalho docente: jornadas e ritmos no cotidiano de professoras e professores. Dissertação (Mestrado em Educação). Faculdade de Educação. Universidade de São Paulo, 2008. 
ALTMANN, H. Orientação sexual nos parâmetros curriculares nacionais. Estudos Feministas, Florianópolis, v. 9, n. 2, p. 575-585, 2001.

ARAÚJO, Joana D’arc Socorro Alexandrino De. Gênero e prática docente no tempo e no espaço de classes multisseriadas: encantos e desencantos de professoras e professores da zona rural de Teresina. Dissertação (Mestrado em Educação). Universidade Federal do Piauí. 2007.

BALESTRIN, Patrícia Abel. Onde "está" a sexualidade? - representações de sexualidade num curso de formação de professoras. Dissertação (Mestrado em Educação). Universidade Federal do Rio Grande do Sul. 2007. 196f.

BARBACELI, Juliana Trindade. Da identidade universitária à identidade profissional docente: a FEUSP e a formação inicial de professores para os primeiros anos de escolarização. 138 f. 2013. Dissertação (Mestrado em Educação) - Faculdade de Educação, Universidade de São Paulo, São Paulo, 2013.

BARBOSA, Tatyana Mabel Nobre. Ressignificação de gênero e da prática docente: aspectos discursivos, cognitivos e representacionais na voz da mulher-professora. Dissertação (Mestrado em Educação), Universidade Federal do Rio Grande Norte, 2002.

BENITES, Maria José de Oliveira. Educação sexual e formação docente: um estudo a partir de concepções discentes. Dissertação (Mestrado em Educação). Universidade Regional de Blumenau. Blumenau. 2006.

BRASIL, Secretaria Especial de Direitos Humanos da Presidência da República. Texto base da 3aㅡ Conferência Nacional De Políticas Públicas de Direitos Humanos de Lésbicas, Gays, Bissexuais, Travestis e Transexuais: "Tema: "Por um Brasil Que Criminalize a Violência Contra Lésbicas, Gays, Bissexuais, Travestis e Transexuais". Nacional de Políticas Públicas e Direitos Humanos de LGBT. Brasília: SEDH, 2016.

BRASIL. Ministério da Educação. Secretaria de Educação Continuada, Alfabetização e Diversidade (Secad). Cadernos SECAD 4 - Gênero e Diversidade Sexual na Escola: reconhecer diferenças e superar preconceitos. Brasília: MEC, 2007.

BRASIL. Presidência da República. Secretaria Especial de Políticas para as Mulheres. Plano Nacional de Políticas para as Mulheres. Brasília: Secretaria Especial de Políticas para as Mulheres, 2004.

BRASIL. Presidência da República. Secretaria Especial de Políticas para as Mulheres. 1o Prêmio Construindo a Igualdade de Gênero - Redações e trabalhos científicos monográficos vencedores -2006, 216p.

BUFALO, Joseane Maria Parice. Nem só de salário vivem as docentes de creche: em foco as lutas do Sindicato dos Trabalhadores no Serviço Público Municipal de Campinas (STMC 1988-2001). Tese (Doutorado em Educação). Universidade Estadual de Campinas. Campinas. 2009. 
CALDAS, Carlos A. A. A escola faz diferença? Um estudo da produção discursiva das homossexualidades por professores de ensino médio. Dissertação (Mestrado em Educação) - UFP, Belém, 2007.

CAMPOS, Elane Silva. Formação docente e relações de corpo, gênero e sexualidade na educação: entendendo conceitos e refletindo ideias. Dissertação (Mestrado em Educação). Universidade Metodista de São Paulo. São Bernardo do Campo.2011.

CAPITANIO, Ana Maria. Gênero e crenças religiosas: sentidos da docência entre professoras do ensino fundamental I. Tese (Doutorado em Educação) -Universidade de São Paulo, São Paulo, 2014.170f.

CARDOSO, Frederico Assis. A identidade de professores homens na docência com crianças: homens fora do lugar? Dissertação (Mestrado em Educação) -Universidade Federal de Minas Gerais, Belo Horizonte, 2004.

CARVALHO, Marie Jane Soares. Gênero, raça e classe social no currículo. 562 f. 1999. Tese (Doutorado em Educação) - Faculdade de Educação, Universidade Federal do Rio Grande do Sul, Rio Grande do Sul, 1999.

CARVALHO, Maria Eulina P.; ANDRADE, Fernando Cézar B.; JUNQUEIRA, Rogério Diniz. Gênero e diversidade sexual: um glossário. João Pessoa: Ed. universitária, UFPB, 2009.

CARVALHO, Eronilda Maria Góis de. Cuidado, relações de gênero e trabalho docente na educação infantil: um estudo de professoras e professores da pré-escola pública. Tese (Doutorado em Educação) Universidade Federal da Bahia, Salvador, 2008.

CASTRO, Nilsandra Martins de. Representações de identidades de gênero e de sexualidade nos discursos de professores de Educação Infantil. Dissertação (Mestrado em Linguística Aplicada) -Universidade Estadual de Campinas, Campinas, 2010.

CASTRO, Roney Polato. Experiência e constituição de sujeitosdocentes: relações de gênero e sexualidades e formação em Pedagogia. 2014. 256 f. Tese (Doutorado em Educação) -Universidade Federal de Juiz de Fora, Juiz de Fora, 2014.

CHAGAS, Patricia Carla de Macedo. Saber ser professora: a constituição da identidade docente. Dissertação (Mestrado em Educação) Universidade Federal do Rio Grande do Norte, 2004.

CHAIGAR, Vânia Alves Martins. A construção de um modo docente de ser: um estudo com alunos do magistério. Dissertação (Mestrado em Educação) -Universidade Federal de Pelotas, 2001.

COLETO, Maytê Gouvêa. Abordagens dos direitos reprodutivos em materiais didáticos para a formação continuada de educadoras(es): uma análise a partir dos editais da SECAD. 2012. Dissertação (Mestrado em Educação). Universidade Estadual Paulista. Faculdade de Ciências e Tecnologia de Presidente Prudente, Presidente Prudente. 161f. 
CONSELHO Nacional de Combate à Discriminação. Brasil Sem Homofobia: Programa de combate à violência e à discriminação contra GLTB e promoção da cidadania homossexual. Brasília: Ministério da Saúde, 2004.

COSTA, Raquel Perpétua Paré da. Coisas de meninos, coisas de meninas: o trabalho docente e a construção das relações de gênero. Dissertação (Mestrado em Educação) Universidade Federal de Pelotas, Pelotas, 2003.

COSTA, Ana Paula. As concepções de sexualidade de um grupo de alunas do curso de Pedagogia: uma análise a partir do recorte de gênero. 136 f. 2009. Dissertação (Mestrado em Educação Escolar) - Faculdade de Ciências e Letras, Universidade Estadual Paulista, Araraquara, 2009.

COSTA, Simone Gomes da. Narrativas audiovisuais e redes de significações sobre gênero e sexualidades nos/com os cotidianos de um curso de formação de professores. 95 f. 2014. Dissertação (Mestrado em Educação) - Faculdade de Educação, Universidade do Estado do Rio de Janeiro, Rio de Janeiro, 2014.

DANILIAUSKAS, Marcelo. Relações de gênero, diversidade sexual e políticas públicas de educação: uma análise do programa Brasil Sem Homofobia. 2011. Dissertação (Mestrado em Educação) - FEUSP, São Paulo, 2011.

EMBIRUSSU, Karina Nery. Formação docente e concepção de gênero: um estudo sobre processos identitário de egressas da Faculdade de Educação da Bahia. Dissertação (Mestrado em Educação) , Universidade Federal da Bahia, Bahia, 2007. 168f.

FERNANDES, Felipe B. M. A Agenda Anti-Homofobia na Educação Brasileira (2003 2010). Tese (Doutorado em Educação) - Universidade Federal de Santa Catarina. Florianópolis, 2011. 422p.

FERRARI, A. Você já deve saber minha “orientação sexual” (se não sabia, ficou sabendo agora, hehe!) - subjetividades e sujeitos em negociação. In: FERRARI, A.. Sujeitos, subjetividades e Educação. 1. ed. Juiz de Fora: editora da UFJF, 2010. v. 1. 272p.

FERREIRA, Vera Laura de Los Santos. A constituição da professora de educação infantil pautada na autonomia: entrelaçando gênero e profissão. Dissertação (Mestrado em Educação), Universidade Federal de Santa Catarina, Santa Catarina, 2003.

FERREIRA, Taisa de Sousa. Entre o real e o imaginário: problematizando o currículo do curso de Licenciatura em Pedagogia em relação a gênero e sexualidade Feira de Santana, BA. 319 f. 2013. Dissertação (Mestrado em Educação) - Faculdade de Educação, Universidade Estadual de Feira de Santana, Feira de Santana, 2013.

FREITAS, Viviane Vieira de. Histórias de vida de mulheres docentes: sexualidade e gênero na educação. Dissertação (Mestrado em Educação), Universidade Federal do Rio de Janeiro, Rio de Janeiro, 2002. 
FONSECA, Thomaz Spartacus Martins. Quem é o professor homem dos anos iniciais? Discursos, representações e relações de gênero. Dissertação (Mestrado em Educação). Universidade Federal de Juiz de Fora, Juiz de Fora, 2011. 141f.

FRANÇA, Lindamara. Educação sexual. Uma análise da concepção dos professores de duas escolas estaduais do ensino fundamental de Curitiba. Dissertação (Mestrado em Educação). Universidade Tuiuti do Paraná. Curitiba. 2008.

FURTADO, Alessandra Cristina. Por uma história das práticas de formação docente: um estudo comparado entre duas escolas normais de Ribeirão Preto-SP (1944-1964). Tese (Doutorado em Educação) -Universidade de São Paulo, 2007. GAMA, Ywanoska Maria Santos da. Gênero no currículo dos anos iniciais do Ensino Fundamental: concepções e vivências de professoras - Recife.147 f. 2004. Dissertação (Mestrado Educação) - Faculdade de Educação, Universidade Federal de Pernambuco, Pernambuco, 2004.

GARCIA, Maria M. Identidade docente. In: OLIVEIRA, D.A.; DUARTE, A.M.C.; VIEIRA, L.M.F. DICIONÁRIO: trabalho, profissão e condição docente. Belo Horizonte:UFMG/Faculdade de Educação, 2010. CDROM.

GARCIA, Leocilda Maria Pacheco. Escutando vozes silenciadas: trabalho, subjetividade e gênero na vida de professoras. Dissertação (Mestrado em Educação) - Pontifícia Universidade Católica do Rio Grande do Sul, 2002.

GATTI, Bernadete. A.; BARRETO, Elba. S. de S.; ANDRÉ, Marli. E. D. A. Políticas docentes no Brasil. Brasília: UNESCO, 2011.

GOMIDES, Wagner Luiz Tavares. Transitando na fronteira: a inserção de homens na docência da Educação Infantil. Dissertação (Mestrado Educação) - Faculdade de Educação, Universidade Federal de Viçosa, Viçosa, 2014.

GRÖSZ, Dirce Margarete. Representações de gênero no cotidiano de professoras e professores. Dissertação apresentada ao Programa de Pós-Graduação em Educação (Mestrado em Educação) - Universidade de Brasília, 2008.

HAMPEL, Alissandra. "A GENTE NÃO PENSAVA NISSO...": educação para a sexualidade, gênero e formação docente na região da Campanha/RS. 194 f. 2013. Tese (Doutorado em Educação) - Faculdade de Educação, Programa de Pós-Graduação em Educação, Universidade Federal do Rio Grande do Sul, Porto Alegre, 2013.

JUNQUEIRA, Rogério Diniz; HENRIQUES, Ricardo; CAMUSCA, Maria Adelaide. Gênero e diversidade sexual na escola: reconhecer diferenças e superar preconceitos. Brasília: Ministério da Educação, 2007.

KOERICH, Maria Cecília Takayama. História de uma presença-ausente: sexualidade e gênero em currículos de pedagogia. 140 f. 2007. Dissertação (Mestrado em Educação) Centro de Ciências da Educação, Universidade Federal de Santa Catarina, Santa Catarina, 2007. 
LEÃO, Maria da Graça Nas tramas da pesquisa-formação: uma abordagem experiencial de autoria feminina no processo de formação docente. 133 f. 2009.

Dissertação (Mestrado em Educação) — Faculdade de Educação, Universidade do Vale do Rio dos Sinos, São Leopoldo, RS, 2009.

LIMA, Tatiane de Lucena. Identidades, currículo e formação docente: um estudo sobre implicações de gênero em práticas educativas de estudantes de pedagogia. $209 \mathrm{f}$. 2008. Dissertação (Mestrado em Educação) - Faculdade de Educação, Universidade Federal da Bahia, Salvador, 2008.

LOPES, Antonio de Padua Carvalho. Beneméritas da instrução - feminização do magistério primário piauiense. Dissertação (Mestrado em Educação). Universidade Federal do Ceará. Ceará. 1996.

LOURO, Guacira L. Educação e docência: diversidade, gênero e sexualidade. Formação Docente, v. 4, p. 1-6. 2011.

MAISTRO, Virginia. I.A. Projetos de Orientação Sexual nas escolas: seus limites e suas possibilidades. 2006 Dissertação (Mestrado em Ensino de Ciências e Educação Matemática) - Centro de Ciências Exatas, Universidade Estadual de Londrina, Londrina. 242f.

MARAFON, Giovanna. 0 ser mulher educada/educadora e os (des) caminhos do feminino na educação. Dissertação (Mestrado em Educação) - Universidade do Federal do Rio de Janeiro, Rio de Janeiro, 2006.

MARTINS, Walkíria de Jesus França. Gênero e sexualidade na formação docente: uma análise no curso de pedagogia da UFMA - São Luís. 2012. 187 f. Dissertação (Mestrado em Educação) — Faculdade de Educação Universidade Federal do Maranhão, São Luís, 2012.

MONTEIRO, Mariana Kubilius. Trajetórias na docência: professores homens na educação infantil. 2014. 152 f. Dissertação (Mestrado em Educação Física) - Faculdade de Educação Física, Universidade Estadual de Campinas, Campinas, 2014.

MOSTAFA, Maria. Professores na encruzilhada entre o público e o privado: o curso Gênero e Diversidade na Escola. Dissertação (Mestrado) - Uerj, Rio de Janeiro, 2009.125f.

MOTTA-ROTH, Désirée; HENDGES, Gabriela Rabuske. Produção textual na universidade. São Paulo: Parábola Editorial, 2010. Série Estratégias de ensino. n. 20.167pp.

NUNES, Maria Dolores de Figueiredo. Relações de gênero e sexualidade no cotidiano escolar: concepções de duas professoras do ensino fundamental. Dissertação (Mestrado em Educação). Universidade Federal de São Carlos, 2002. 207p.

OLIVEIRA, Auta Sirlei Barbosa. Reflexos no espelho: gênero masculino no magistério. Dissertação (Mestrado em Educação). Universidade Federal de Pelotas. Pelotas/RS. 2002. 
OLIVEIRA, Dalila A. Política educacional. In: OLIVEIRA, D.A.; DUARTE, A.M.C.; VIEIRA, L.M.F. DICIONÁRIO: trabalho, profissão e condição docente. Belo Horizonte:

UFMG/Faculdade de Educação, 2010. CDROM.

PEREIRA, Flávia Goulart. Homens no curso de pedagogia: “as razões do improvável. Dissertação de Mestrado apresentada ao Programa de Pós-graduação em Educação: conhecimento e inclusão social, da Universidade Federal de Minas Gerais. 2013. $146 f$.

PEREIRA, Isabelle Sanches. Identidade de raça-gênero na formação docente: história de vida de professores nos cenários familiares. Dissertação (Mestrado em Educação) Universidade Estadual da Bahia, Salvador, 2006. 129f.

RAMOS, Joaquim. Um estudo sobre os professores homens da educação infantil e as relações de gênero na rede municipal de Belo Horizonte. Dissertação (Mestrado). Pontifícia Universidade Católica de Minas Gerais. Belo Horizonte. 2011.139f.

REIS, Greissy Leoncio. 0 gênero e a docência: uma análise de questões de gênero na formação de professores do Instituto de Educação Euclides Dantas. Dissertação (Mestrado em Educação). Universidade Federal da Bahia. 2011.194f.

RIBEIRO, Simone da Silva. Trabalho docente: vocação para o magistério, qualificação para o trabalho e relações de gênero - a fala das professoras das primeiras séries do ensino fundamental. Dissertação (Mestrado em Educação) - Universidade do Estado do Rio Janeiro, Rio de Janeiro, 1998.

RIZZA, Juliana Lapa. A sexualidade no cenário do ensino superior: um estudo sobre as disciplinas nos cursos de graduação das universidades federais brasileiras. 2015. 145 f. Tese (Doutorado em Educação Ambiental) - Instituto de Educação, Universidade Federal do Rio Grande, Cidade, 2015.

RIZZATO, Liane Kelen. Percepções de professores/as sobre gênero, sexualidade e homofobia: pensando a formação continuada a partir de relatos da prática docente. 2013. Dissertação (Mestrado em Educação) - Faculdade de Educação, São Paulo, 2013.

ROSA, Fábio José Paz da. 0 dispositivo da sexualidade enquanto enunciador do professor-homem no magistério das séries iniciais e na educação infantil. 2012. 159 f. Dissertação (Mestrado em Educação, Cultura e Comunicação) - Faculdade de Educação da Baixada Fluminense, Universidade do Estado do Rio de Janeiro, Rio de Janeiro, 2012.

ROSSI, Alexandre J. Avanços e limites da política de combate à homofobia: uma análise do processo de implementação das ações para a educação do programa Brasil sem homofobia. 2010. 186f. Dissertação (Mestrado em Educação) Universidade Federal do Rio Grande do Sul, Porto Alegre, 2010.

ROSEMBERG, Fúlvia; MADSEN, Nina. Educação formal, mulheres e gênero no Brasil contemporâneo. In: BARNSTED, Leila Linhares; PITANGUY, Jacqueline. (Orgs.). 0 progresso das mulheres no Brasil 2003-2010. Rio de Janeiro: CEPIA; Brasília: ONU Mulheres, 2011. p. 390-434. 
SANTOS, Daniele Vasco. Documentos de subjetivação: um estudo sobre o currículo em um programa de formação em gênero. Dissertação (Mestrado em Educação). Universidade Federal do Pará. 2009.

SANTOS, Tatiana Cavanha. Formação inicial docente: a escola normal do Colégio Sagrado Coração de Jesus (1946-1971). Dissertação (Mestrado em Educação). Universidade Tuiuti do Paraná. 2006.

SANTOS, Valéria Lopes dos. Representações de gênero nas falas das professoras da pré-escola e primeiro ano do ensino fundamental que atuam no município de Corumbá, MS. Dissertação (Mestrado em Educação). Universidade Federal de Mato Grosso do Sul. 2011.115f.

SANTOS, Elizabeth Angela dos. Gênero e profissão docente: as representações sociais das alunas egressas do curso de Pedagogia da Faculdade de Ciências e Tecnologia/UNESP, campus de Presidente Prudente. 2008. 106 f. Dissertação (Mestrado em Educação) - Faculdade de Ciências e Tecnologia, Universidade Estadual Paulista, Presidente Prudente - SP, 2008.

SANTOS, Ana Cristina Ferreira dos. Gênero, sexualidade e diversidade na formação de professores da rede municipal de Juiz de Fora. Petrópolis: Universidade Católica de Petrópolis. Mestrado em Educação, 2012. 147p.

SARAIVA, Simone Rocha. Até onde vou? Até onde somos? A professora da RME de Porto Alegre: construções em movimento. Dissertação (Mestrado em Educação) Universidade Federal do Rio Grande do Sul, Porto Alegre, 2003.

SCOTT, Joan W. Gênero: uma categoria útil de análise histórica. Educação e realidade, Porto Alegre, v. 16, n. 2, p. 5-22, jul./dez. 1990.

SILVA, Carmedite Moreira Santos. Relação escola e famílias homoafetivas: visão de discentes de Licenciatura em pedagogia. 2012. 118 f. Dissertação (Mestrado em Família na Sociedade Contemporânea) - Universidade Católica do Salvador, Salvador, 2012.

SILVA, Peterson Rigato da. Não sou tio, nem pai, sou professor! A docência masculina na educação infantil. Dissertação (Mestrado Educação) - Universidade Estadual de Campinas, Campinas, 2014.

SILVA, Sirlene Mota Pinheiro da. A mulher professora e a sexualidade: representações e práticas no espaço escolar. Dissertação (Mestrado em Educação). Universidade Federal do Maranhão- UFMA. São Luís, 2009. 159 f.

SILVEIRA, Saionara Oliveira Bello. Mulheres professoras tecidas nas tramas de suas relações cotidianas. 2006. 119 f. Dissertação (mestrado) - Universidade do Estado de Santa Catarina, Centro de Ciências da Educação, Programa de Pós-Graduação em Educação e Cultura, 2006. 
SOARES, A. G. Mapeamento de teses e dissertações sobre gênero, diversidade sexual e formação inicial docente no Brasil

SOARES, Alexandre G. A inserção de disciplinas de gênero em cursos de Pedagogia de Faculdades de Educação: caminhos e desafios em três universidades federais em Minas Gerais. Tese (Doutorado em Educação). São Paulo. 2018. 169f.

SOUZA, Karina Valdestilhas Leme de. A prática da leitura na escola e as relações de gênero e sexualidade: subsídios para reflexão inicial e continuada de professores(as). 2014. 184 f. Dissertação (Mestrado em Educação) - Faculdade de Educação, Universidade de São Paulo, São Paulo, 2014.

TARDIF, Maurice, LESSARD, Claude e LAHAYE, Louise. Os professores face ao saber. Esboço de uma problemática do saber docente. Teoria e Educação nํ4, Porto Alegre: Pannônica, 1991.

TARDIF, Maurice. Saberes docentes e formação profissional. Petrópolis, R.J.: Editora Vozes, 2002.

UNBEHAUM, Sandra Gouretti. As questões de gênero na formação inicial de docentes: tensões no campo da educação. Tese (Doutorado em Educação) - Pontifícia Universidade Católica de São Paulo, São Paulo, 2014.

UNBEHAUM, Sandra; CAVASIN, Sylvia; GAVA, Thais. Gênero e sexualidade nos currículos de Pedagogia. Fazendo Gênero 9: Diásporas, diversidades e deslocamentos.

Florianópolis, 2010.

VASCONCELOS, Fabio. A mulher professora: gênero e formação. Dissertação (Mestrado em Educação). Universidade de Uberaba, Uberaba, 2003.104f.

VIANNA, Cláudia Pereira. O movimento LGBT e as políticas de educação de gênero e diversidade sexual: perdas, ganhos e desafios. Educação e Pesquisa - Revista da Faculdade de Educação da USP, v. 41, p. 791-806, 2015.

VIANNA, Cláudia Pereira; CARVALHO, Marilia Pinto de, SCHILLING, Flavia Inês; MOREIRA, Maria de Fatima Salum. Gênero, sexualidade e educação formal no Brasil: uma análise preliminar da produção acadêmica entre 1990 e 2006 . Educação \& Sociedade, Campinas, v. 32, n. 115, pp. 525-545, 2011.

VIANNA, Cláudia. Estudos de gênero, sexualidade e políticas públicas de educação: das ações coletivas aos planos e programas federais. 2011. 253f. (Tese de Livre Docência. Área de Concentração: Gênero e Educação) - Universidade de São Paulo Faculdade de Educação, São Paulo, 2011.

VIANNA, Cláudia. Gênero, sexualidade e políticas públicas de educação: um diálogo com a produção acadêmica. Pro-Posições,[on-line], v. 23, n. 2, pp. 127-143, 2012. Disponível em:http://www.scielo.br/scielo.php?script=sci_arttext\&pid=S0103-

73072012000200009. Acesso em: 18 fev. 2016.

VIANNA, Cláudia; UNBEHAUM, Sandra. Gênero na educação básica: quem se importa?: uma análise de documentos de políticas públicas no Brasil. Educação \& Sociedade, Campinas, v. 28, n. 95, p. 407-428, maio/ago. 2006. 
VIANNA, Cláudia; UNBEHAUM, Sandra. 0 gênero nas políticas públicas de educação no Brasil: 1988-2002. Cadernos de Pesquisa, São Paulo, v. 34, n. 121, p. 77-104, jan./abr. 2004.

VIEIRA, Nelma Bernardes. A questão de gênero no magistério: a presença masculina no Curso Normal. Dissertação de Mestrado. Universidade Católica de Petrópolis. Petrópolis,2012.

VIEIRA, Andrea Amorim. A feminização do magistério de séries iniciais da rede pública do Distrito Federal. Dissertação (Mestrado em Educação). Universidade de Brasília, Brasília, 2003.

VIEIRA, Marco Antonio. Magistério no Brasil: obscura gênese. Dissertação (Mestrado em Educação) Universidade Federal Fluminense, Rio de Janeiro, 1998.

YANNOULAS, Silvia. C.; BARBOSA, Marcia; LOMBARDI, Maria Rosa; OLIVEIRA, Talita. S.; VIANNA, Cláudia; DIAS, Marly J. S.; TEIXEIRA, Marlene; GOREN, Nora ; MARCONDES, Mariana. ; CARRILHO, Anabelle . A feminização do magistério na Educação Básica e os desafios para a prática e a identidade coletiva docente. In: Silvia Cristina Yannoulas. (Org.). Trabalhadoras: análise da feminização das profissões e ocupações. 1ed. Brasília: Abaré, 2013, v., p. 159-180.

WELK, Rosane. 0 diário da professora D.: entre dizeres e (a)fazeres do contar-se. Dissertação (Mestrado em Educação) -Universidade Estadual de Santa Catarina, Santa Catarina, 2003.

WELLER, Wivian; PAZ, Cláudia Denís Alves. Gênero, raça e sexualidade nas políticas educacionais: avanços e desafios. Disponível em <http://www.anpae.org.br/simposio2011/cdrom2011/PDFs/trabalhosCompletos/com unicacoesRelatos/0549.pdf>. Acesso em: 30 out. 2013. 


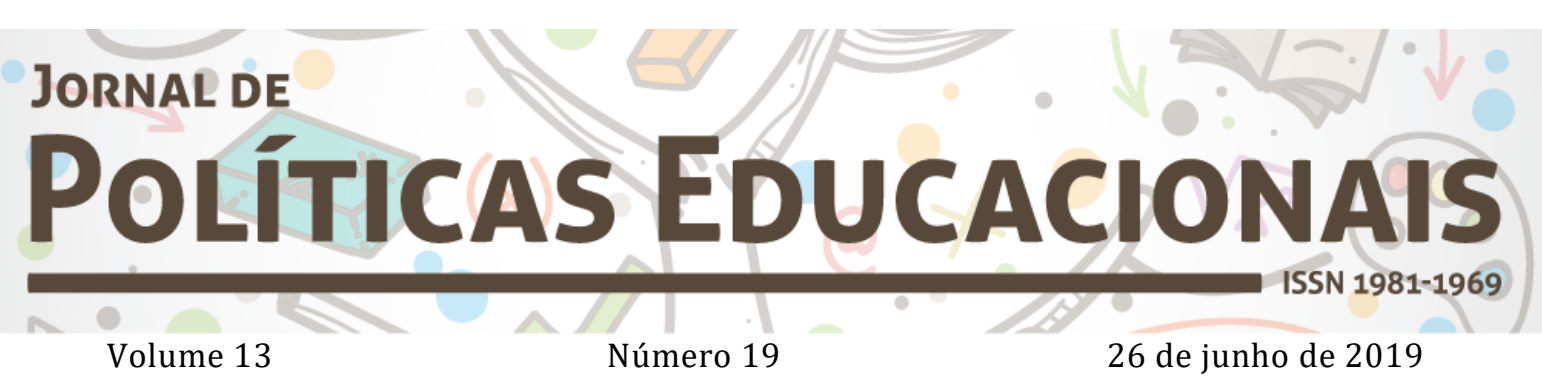

\begin{abstract}
(c)
SORAERIGHIS RESERVED O Copyright é retido pelo/a autor/a (ou primeiro co-autor) que outorga o direito da primeira publicação ao Jornal de Políticas Educacionais. Mais informação da licença de CreativeCommons encontram-se em http://creativecommons.org/licenses/by-nc-nd/2.5. Qualquer outro uso deve ser aprovado em conjunto pelo/s autor/es e pelo periódico.

JoRnAl DE Políticas EduCACIONAIS é uma publicação do Núcleo de Políticas Educacionais do Setor de Educação da Universidade Federal do Paraná - NuPE/UFPR, em consórcio com a Linha de Pesquisa em Políticas Educacionais do Programa de Pós-Graduação em Educação - PPGE/UFPR, que aceita colaboração, reservando-se o direito de publicar ou não o material espontaneamente enviado à redação. As colaborações devem ser enviadas ao NuPE/UFPR, conforme orientações contidas nas páginas do periódico na internet: http://revistas.ufpr.br/ipe.
\end{abstract}

\author{
Indexação: \\ BBE - Biblioteca Brasileira de Educação (MEC/INEP) \\ Clase (Base de Datos Bibliográfica de Revistas de Ciencias Sociales y Humanidades) \\ Diadorim - Diretório de Política de Acesso Aberto das Revistas Científicas Brasileiras (IBICT) \\ Google Scholar \\ Index Copernicus \\ Portal de Periódicos (CAPES) \\ SER - Sistema Eletrônico de Revistas da Universidade Federal do Paraná (SER/UFPR) \\ Sumários de Revistas Brasileiras (FUNPEC-RP) \\ DRJI - Directory of Research Journals Indexing
}

(Periódico integralmente disponível apenas em via eletrônica)

Jornal de Políticas Educacionais / Núcleo de Políticas Educacionais da Universidade Federal do Paraná NuPE/UFPR - v.1, n. 1 (1ํs semestre de 2007) - Curitiba: NuPE/UFPR.

Volume 13, número 19 - Junho de 2019

ISSN 1981-1969

1. Educação - Periódicos. 2. Política Educacional - Periódicos. I. NuPE/UFPR

Comitê Editorial:

Elisângela Scaff (UFPR)

Daniela de Oliveira Pires (UFPR)

Ana Lorena Bruel (UFPR)

Conselho Editorial:

Andréa Barbosa Gouveia (UFPR), Ângela Hidalgo (UNICENTRO), Cesar Gernomino Tello (Universidad Nacional TresFebrero, Argentina), Gladys Beatriz Barreyro (USP), Juca Gil (UFRGS), Jefferson Mainardes (UEPG), João Ferreira de Oliveira (UFG), Luiz Souza Júnior (UFPB), Marcos Edgard Bassi (UFSC), Regina 
SOARES, A. G. Mapeamento de teses e dissertações sobre gênero, diversidade sexual e formação inicial docente no Brasil

Maria Michelotto (UFPR), Robert Verhine (UFBA), Rosana Cruz (UFPI), Rubens Barbosa Camargo (USP), Sebastián Donoso Díaz (Universidad de Talca, Chile), Taís Moura Tavares (UFPR), Theresa Adrião (UNICAMP), Vera Peroni (UFRGS).

Créditos e Agradecimentos:

Revisão de Língua Portuguesa, Abstract e Resumen: PROGRAMA DE APOIO ÀS PUBLICAÇÕES CIENTÍFICAS PERIÓDICAS DA UFPR

Arte e diagramação: TIAGO TAVARES (iagotav@gmail.com)

Jornal de Políticas Educacionais

Universidade Federal do Paraná

Setor de Educação

Núcleo de Políticas Educacionais - NuPE/UFPR

Avenida Sete de Setembro, 2645

$2^{\circ}$ andar, Sala 213

80.230-010 - Curitiba - PR - Brasil

Tel.: 41-3535-6264

jpe@ufpr.br

http://revistas.ufpr.br/jpe 